\title{
PENGEMBANGAN WAHANA WISATA JONGGOL DI DUSUN BALANGAN, WUKIRSARI, CANGKRINGAN
}

\author{
Putri Rachmawati $^{1)}$, Linda Kusumastuti ${ }^{2)}$, Desi Susilawati ${ }^{2)}$ \\ 1) Program Vokasi, Teknik Mesin, Universitas Muhammadiyah Yogyakarta \\ ${ }^{2)}$ Program Vokasi, Akuntansi Terapan, Universitas Muhammadiyah Yogyakarta \\ putri.rachmawati@umy.ac.id
}

DOI : 10.31604/jpm.v2i1.13-20

\begin{abstract}
KKN-PPM is an empowerment program that will be implemented in Dukuh Balangan, Wukirsari Village, Cangkringan District, Sleman Regency, D.I. Yogyakarta aims to focus on the development and packaging of jonggol tourism vehicles in Balangan needs to be implemented to realize outbound education tours and camping ground. Which has selling power by highlighting the uniqueness, and the authenticity of nature around the Balangan hamlet? This service uses observation, interview, and education methods. In this educational method, the ESD method is used which provides counseling, socialization, training, and implementation. The result of dedication is the availability of outbound vehicles, garbage disposal, and places of worship/ so that tourist attractions can be better in tourism management, and a tool for sustainable tourism development.
\end{abstract}

Keywords: KKN PPM, Observation, Interview, ESD (Education for Sustainable Development) method, Jonggol Tourism.

\begin{abstract}
Abstrak
KKN PPM adalah program pemberdayaan yang akan dilaksanakan di Dukuh Balangan, Desa Wukirsari, Kecamatan Cangkringan, Kabupaten Sleman, D.I. Yogyakarta bertujuan berfokus tentang pengembangan dan pengemasan wahana wisata jonggol di Balangan perlu dilaksanakan agar terwujud wisata edukasi outbond dan camping ground. Yang memiliki daya jual dengan menonjolkan kekhasan, dan keaslian alam di sekitar dusun Balangan. Pengabdian ini menggunakan metode observasi, wawancara dan edukasi. Pada metode edukasi ini menggunakan metode ESD dimana mengadakan penyuluhan, sosialisasi, pelatihan dan implementasi. Hasil pengabdian adalah sudah tersedianya wahana outbond, pembuangan sampah, dan tempat ibadah, sehingga tempat wisata jonggol bisa lebih baik dalam pengelolaan wisata, dan wahana dalam pengembangan wisata berkelanjutan.

Kata kunci: KKN PPM, Metode Observasi, Interview, ESD (Education for Sustainable Development), Wisata Jonggol.
\end{abstract}




\section{PENDAHULUAN}

Yogyakarta adalah daerah istimewa setingkat provinsi di Indonesia yang merupakan peleburan Negara kesultanan Yogyakarta dan Negara Kadipaten Paku Alaman. Daerah Istimewa Yogyakarta terletak di bagian selatan Pulau Jawa, dan berbatasan dengan Provinsi Jawa Tengah dan Samudra Hindia. Yogyakarta yang memiliki 4 Kabupaten, yaitu Kabupaten Sleman, Kabupaten Bantul, Kabupaten Gunung Kidul, dan Kota Yogyakarta yang terdiri atas 78 daerah kecamatan serta 438 Kelurahan atau desa dan satu kotamadya. Dengan Jumlah lebih dari 400 kelurahan ribuan KK pada satu dusun. Kota Yogyakarta yang lebih dari 5 kali meraih penghargaan Adipura, dan penghargaan Pasar tradisional bersih dan terbaik serta hutan menunjukkan bahwa warga dan pemerintah Kota Yogyakarta selalu berkomitmen untuk menjaga lingkungan.

KKN PPM di Dusun Balangan, Kelurahan Wukirsari, Kecamatan Cangkringan, Kabupaten Sleman Yogyakarta memiliki beberapa kelompok, seperti Kelompok Tani Gemilang, Kelompok perikanan Mina Gemilang, Kelompok PKK, Kelompok DARWIS (Sadar Wisata), Kelompok Seni dan masih ada beberapa jenis kelompok. Dengan 1 RT dan 1 RW dan terdiri dari $70 \mathrm{KK}$. Dusun Balangan yang bagian dari Desa Wukirsari secara topografi terletak pada kaki gunung merapi dengan ketinggian $400-600 \mathrm{~m}$ diatas permukaan laut. Jenis tanah regosol yaitu berasal dari material gunung api, jadi sangat subur dan sangat cocok untuk area pertanian. Dari sisi geografis terletak pada ketinggian 600 mdpl dengan suhu udara rata - rata $25^{\circ} \mathrm{C}$. Potensi unggulan Desa adalah CV. Tani Organik Merapi, Perikanan Mina Gemilang dan camping ground
Jonggol yang sangat cocok sebagai desa agrowisata organik.

Dusun Balangan, merupakan pedukuhan yang terdapat pada Desa Wukirsari, Kecamatan Cangkringan, Kabupaten Sleman Daerah Istimewa Yogyakarta. Dusun ini terletak di kaki Gunung Merapi sebelah Selatan. Dusun Balangan memiliki alam yang sangat asri, wilayahnya sebagian besar adalah area persawahan yang latar belakangnya pemandangan Gunung Merapi yang terlihat indah. Kelompok tani gemilang dengan kearifan lokal dalam budidaya pertanian telah mengembangkan Tanaman Organik Merapi (TOM) merupakan metode pemasaran tanaman organik yang mana produknya dari petani 1 dusun. Adapun kelompok PKK (Pesona Bunda), Posyandu, dan Kelompok Tari (Gemilang). Dusun Balangan ini berada pada daerah aliran sungai kuning, sehingga memiliki ketersediaan air yang cukup sehingga pada wilayah ini juga mengembangkan kelompok perikanan dengan nama Mina Gemilang dan yang paling menarik dari Dusun ini adalah dengan daerah yang kaya akan kuliner ada tempat yang dimanjakan dengan pesona alam yang begitu menantang untuk kegiatan outbound dengan ada fasilitas untuk camping ground. Sehingga, Dusun Balangan bisa untuk merepresentasikan sebuah brand, wisata alam TOM (Tanaman Organik Merapi) dengan tampak langsung Gunung Merapi, air yang masih jernih, dan udara yang asri. Branding yang tepat berguna untuk menarik konsumen agar menggunakan wisata yang ditawarkan dan bisa mempertahankan eksistensi dari suatu brand (Hasan, 2013). Penggunaan brand pada suatu destinasi wisata dimaksudkan sebagai ciri khas atau kekhasan dari produk wisata lainnya (Assauri, 2012). Pengelola Darwis (Sadar Wisata) sendiri ingin 
mewujudkan dusun Balangan ini sebagai kampung wisata edukasi outbond dan camping ground.

Akan tetapi, aktual dilapangan membuktikan bahwa pengembangan wisata di dusun Balangan belum cukup representatif sebagai kampung wisata bernuansa edukasi outbond dan camping ground. Walaupun tempat wisata sendiri sudah ada, akan tetapi wahana untuk outbond sendiri masih tergolong minim sekali. Letak untuk camping ground sendiri masih belum terawat dengan bagus, sehingga untuk tema edukasi outbond sendiri masih banyak fasilitas dan wahana pendukung sehingga bisa diangkat sebagai brand dusun wisata Balangan.

Kunci sukses pengembangan destinasi wisata terletak pada persoalan pengemasan daya tarik wisata. Sejauh mana daya tarik wisata yang ditawarkan memiliki keunikan, keindahan, keaslian, dan nilai yang dapat mempengaruhi kepuasan wisatawan sehingga berdampak pada loyalitas pengunjung (Hermawan, 2017; Brahmanto, 2016). Sehingga diperlukan juga pengemasan daya tarik wisata untuk lebih menonjolkan sisi kekhasan sebagai nilai jual (Ainurrahman, 2010).

Oleh karena itu, pengabdian masyarakat ini berfokus tentang pengembangan dan pengemasan wahana wisata jonggol di Balangan perlu dilaksanakan agar terwujud wisata edukasi outbond dan camping ground. Yang memiliki daya jual dengan menonjolkan kekhasan, dan keaslian alam di sekitar dusun Balangan.

\section{METODE PELAKSANAAN}

Pengabdian masyarakat ini berfokus pada pemberdayaan untuk meningkatkan tata kelola termasuk pada wahana wisata Jonggol sehingga bisa mempunyai kekhasan dari dusun
Balangan. Berbagai permasalahan yang ada untuk mendapatkan data pelu untuk rekomendasi supaya bisa implementatif. Permasalahan yang ada dikaji dengan pengumpulan data yang digunakan adalah wawancara dan observasi. Wawancara dilakukan secara langsung dengan warga dusun Balangan. Metode observasi dilakukan dengan melakukan pengamatan langsung pada proses entry data, diskusi langsung dengan kelompok darwis, serta sosialisasi dengan pesona bunda. Memberikan pelatihan, perancangan, diskusi langsung, brainstorming bareng dengan kelompok untuk membuat desa wisata yang bisa merukunkan warga.

Data dan fakta hasil pengumpulan data yang sudah terkumpul akan disusun, dijelaskan dan di analisa dengan menggunakan pendekatan deskriptif. Berikut hasil analisa dengan metode pendekatan deskriptif:

1) Metode Observasi : Tahap metode ini dilaksanakan pada tanggal 03 Januari sampai dengan 16 Januari 2018. Pencarian informasi ini dilakukan dengan menggunakan metode wawancara langsung (Metode pengumpulan data dengan mengamati langsung dan mengadakan tanya jawab secara langsung kepada kelompok darwis, kelompok tani, kelompok pesona bunda. dan studi literatur (Suatu teknik pengumpulan data di lapangan dan mengumpulkan informasi dengan cara mempelajari buku buku ilmiah yang menunjang pembuatan pengabdian), meliputi : ketua pengelola tiap kelompok, dan staff pengelola kelompok Darwis, serta pelaku usaha pendukung.

2) Metode pengamatan langsung dan melihat potensi wahana wisata di dusun Balangan, terutama pada tata kelola dan wahana yang ada di 
tempat wisata. Pada tahap pencarian informasi data lapangan ini dilakukan pada tanggal 10 Januari 2018 sampai dengan 18 Januari 2018. Sedangkan metode analisis data dilakukan dengan metode ESD. Metode ESD (Education for Sustainable Development) yaitu metode pembelajaran fungsinya mendukung pembangunan berkelanjutan,sehingga masyarakat bisa saling keterkaitan bersinambungan, memberikan kesadaran dan kemampuan untuk mendorong masyarakat berpikir konstruktif dan kreatif dalam menghadapi tantangan global serta menciptakan masyarakat tangguh secara kontinu dan berkelanjutan. Metode ESD memiliki 3 pilar yang sangat mendasar yaitu ekologi, ekonomi dan sosial. Ketiga pilar tersebut saling berhubungan dan keterkaitan satu dengan yang lainnya.

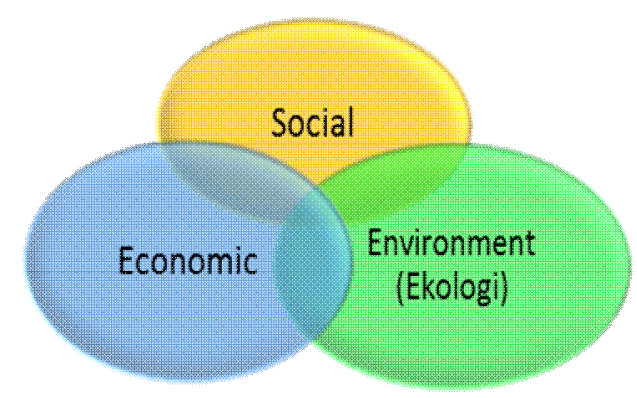

Gambar 1: Pilar dalam ESD

Metode ESD yang akan dilakukan dalam KKN PPM UMY akan fokus pada pembelajaran untuk kelompok DARWIS (Sadar Wisata) sebagai pokok sasaran. Metode ESD ini menyesuaikan dengan kondisi sekitar serta memanfaatkan potensi lokal yang ada di kawasan dusun Balangan.
Beberapa materi pembelajaran yang akan di fokuskan pada peningkatan wisata Jonggol dan pengelolaan air. Melalui implementasi metode ESD diharapkan mampu mengembangkan, dan mengimplementasikan rencana kegiatan yang mengarah kepada sustainable development, yaitu dengan beberapa langkah pelaksanaan:

1) Memberikan edukasi terhadap kelompok tani, tari, dan Darwis untuk bersinergi membangun kekhasan dari wisata di dusun Balangan, seperti : penyuluhan terhadap warga.

2) Memberikan sosialisasi bagaimana mendorong masyarakat yang tangguh, berpikir konstruktif dan kreatif.

3) Partisipatif development masyarakat sehingga saling bersinergi.

Rekomendasi tata kelola wana wisata outbond dan camping ground dapat diperoleh melalui strategi boosting, yaitu membuang faktor faktor yang tidak menguntungkan dan memperbaiki atau menguatkan faktor faktor yang menjadi keuntungan dalam pengelolaan untuk dapat dilakukan langkah implementasinya (Ashley, 2006).

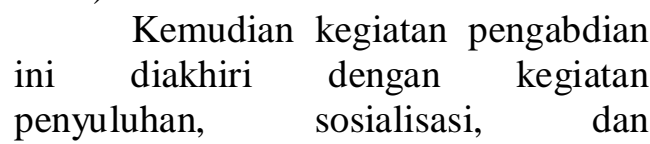
penambahan wahana wisata terutama untuk tempat ibadah, edukasi arena outbond dan camping ground. Pengabdian masyarakat ini dilaksanakan pada tanggal 16 Januari 2018 sampai dengan 17 Februari 2018, sehingga bisa digambarkan alur kegiatan pengabdian masyarakat secara kesuluruhan adalah sebagai berikut: 
Putri Rachmawati, dkk. Pengembangan Wahana Wisata Jonggol di...

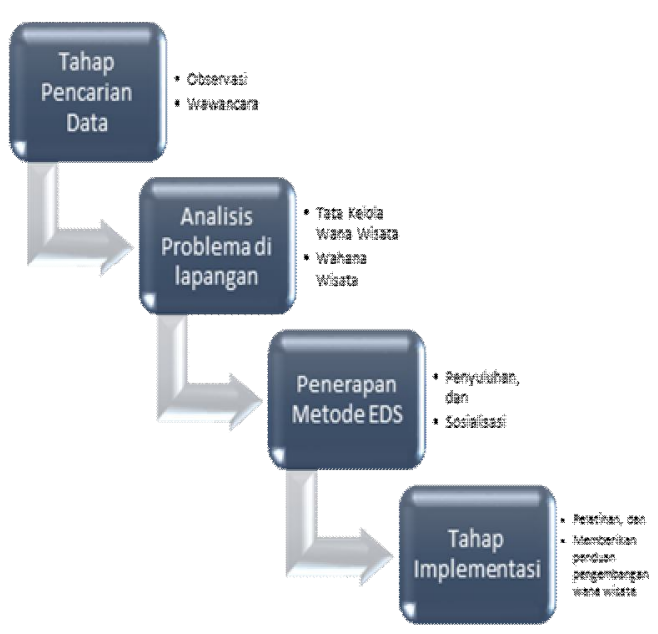

Gambar 2: Alur Kegiatan Pengabdian Masyarakat

\section{HASIL DAN PEMBAHASAN}

Pengembangan tata kelola dan wahana wisata di dusun Balangan merupakan destinasi wisata edukasi outbond dan camping ground yang terletak di Jl. Cangkringan, Sembungan, Umbulmartani, Ngemplak, Kabupaten Sleman, Daerah Istimewa Yogyakarta 55584 tempat yang sangat strategis dipinggir jalan raya dan sangat mudah untuk dijangkau.

Dusun Balangan menawarkan tema wisata yang sangat memanjakan mata, menikmati berbagai potensi alam yang masih asri dengan pandangan langsung Gunung Merapi, membuat wahana permainan outbond berbagai edukasi di dalamnya, yaitu :

1) Permainan air : pemanfaatan kolam bisa melatih berbasis ESD (Education for Sustainable Development) ini mempunyai tujuan sebagai berikut: melatih keberanian, komunikasi baik, kreativitas dan problem solving.

2) Permainan tali : Tujuan untuk melatih dan menahan keseimbangan serta melatih kekompakan, menjadikan arena outbond lebih banyak edukasi didalamnya.

3) Camping Ground : merupakan area yang hanya untuk camping, sehingga tempat juga memadai dengan tanah yang datar dan dimanjakan dengan pemandangan.

4) Tempat sampah : pembuangan sisa makanan, plastik, dan sejenis sampah organik maupun anorganik yang sering ditinggalkan oleh para pengunjung dibuat terpisah dan tiap sudut tempat sudah disediakan, dari situ bisa untuk melatih edukasi pengunjung supaya bisa menciptakan kebersihan sendiri, sehingga pengunjung pun tidak kesusahan dalam mencari tempat pembuangan sampah.

5) Tempat Ibadah : tempat wisata di dusun Balangan ini perlu ada, karena jika para pengunjung datang tidak mencari-cari lagi tempat untuk ibadah.

Kelima wahana dan sarana yang belum ada, di buat untuk tempat wisata jonggol di dusun Balangan sehingga terwujud sebagai kawasan wisata yang asri bersih dengan memanfaatkan air gunung yang jernih dan bersih serta sadar akan merawat dan sarana berbasis ESD (Education for Sustainable Development). Selain potensi fisik yang dikembangkan, dari sisi non fisik, yaitu edukasi dengan memperhatikan aspek produktivitas manusia dan ilmu pengetahuan tentang menciptakan wisata yang bersih, cerdas dan mandiri. Sehingga pada potensi non-fisik, adalah ;

1) Penyuluhan tentang tata kelola kelompok Darwis, sehingga masyarakat dapat mengetahui lebih banyak tentang sistem tata kelola yang baik. Dengan ditunjukkan pada langkah langkah dibawah ini: 


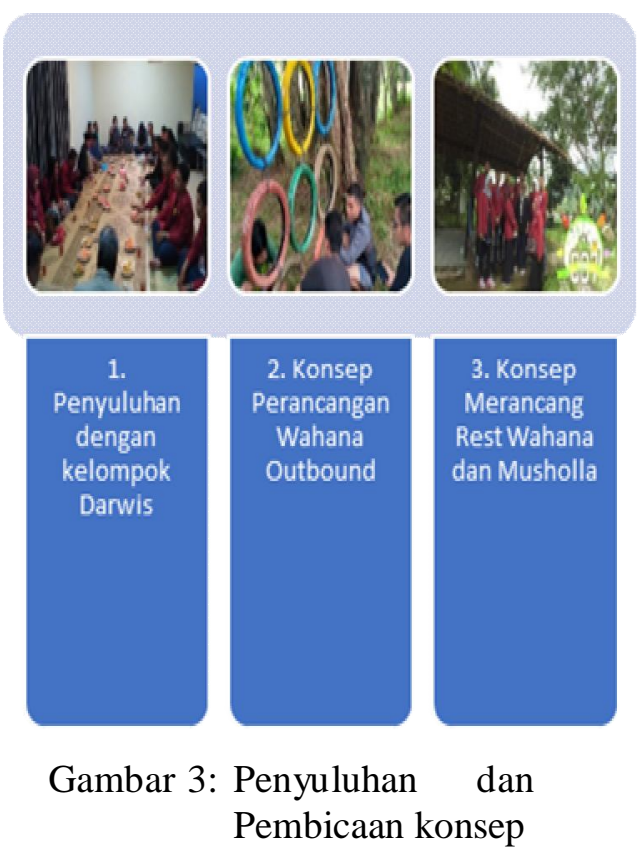

2) Pendampingan dan perancangan konsep di tiap kelompok khususnya untuk kelompok Darwis, supaya masyarakat dapat mengetahui bagaimana mengelola wisata yang baik, dan cara pemasarannya. Sudah dikaji pada gambar 2. Bahwa pendampingan dalam pembuatan wahana outbond untuk pembelajaran (edukasi) masyarakat saat dipakai untuk outbond.

3) Sosialisasi, pemahaman, diskusi dan hasil konsep rancangan.

4) Seminar dan pelatihan tentang hidup bersih di tempat wisata

5) Implementasi langsung ke tempat wisata Jonggol.

Dari uraian diatas bisa dilihat potensi yang paling banyak adalah tempat wisata jonggol di dusun Balangan. Pengertian sederhana wisata edukasi adalah upaya meningkatnya pengetahuan baru melalui kegiatan wisata (Pevzner \& Nikolaeva, 2017). Melihat fakta dilapangan, wisata jonggol terlihat cukup memadai untuk tempat wisata outbond dan camping ground, walaupun belum bisa dikatakan representatif. Akan tetapi, wahana untuk outbond dan camping ground tetap belum bisa maksimal walaupun, sudah beberapa di bangun untuk media outbond dan pelengkap dalam tempat wisata. Faktor pendukung yang perlu di kembangkan adalah perlu adanya media informasi, seperti ; papan informasi yang bisa menjelaskan sesuatu, jadi tidak hanya media outbond saja. Selain itu, dalam pengelolaan suatu wisata perlu adanya pelayanan yang mampu membuat tertarik tempat wisata tidak hanya untuk area outbond dan camping ground tapi juga menonjolkan keunggulan pada tempat wisata tersebut, seperti ; adanya flying fox, susur sungai, fishing, dll. sehingga, pelanggan pun bisa banyak menikmati permainan, dan camping juga bisa mendapatkan suasana yang nature. Selain itu, pemberdayaan pengelola bisa dilatih edukasi seminar dan pelatihan serta pendampingan lebih lanjut, sehingga bisa dibuat portal wisata dan menambah pengetahuan tentang tata kelola dan pemasaran yang menarik dan lebih terjual nilai ekonominya.

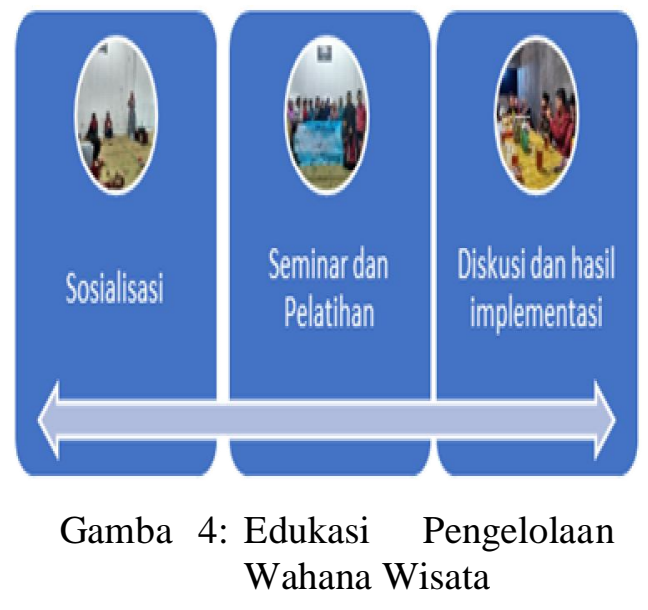

Termasuk juga kegiatan brainstorming untuk anak - anak dengan memanfaatkan tempat wisata, seperti pada gambar 5 . 
Putri Rachmawati, dkk. Pengembangan Wahana Wisata Jonggol di...

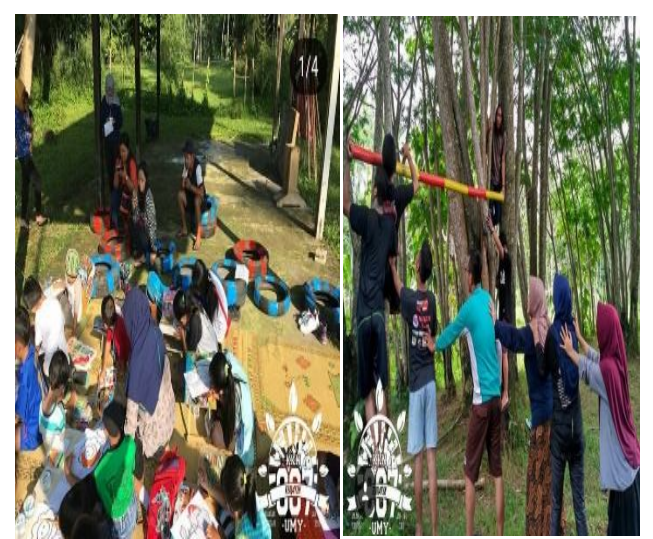

Gambar 5: Edukasi permainan

Penambahan tempat ibadah, dan tempat istirahat sehingga pengunjung tidak kesusahan saat mencari tempat ibadah dan istirahat, seperti gambar 6 .

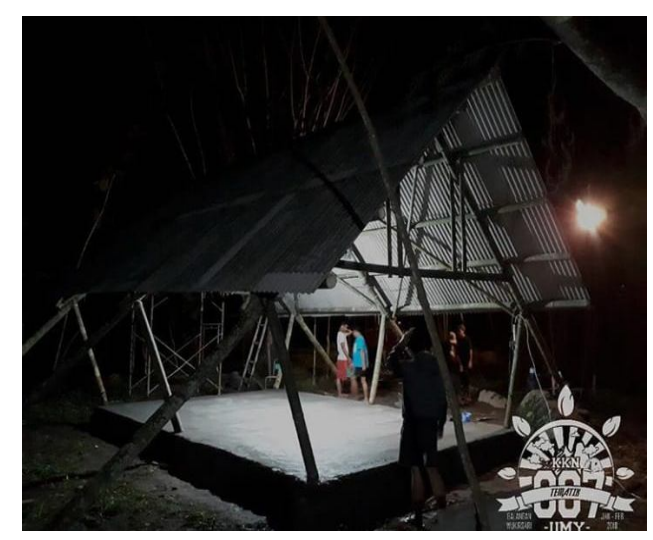

Gambar 6: Tempat Ibadah dan istirahat

Selain beberapa poin diatas, mewujudkan pengembangan pengelolaan wisata berkelanjutan sehingga pengelolaan perlu perbaikan dalam tata kelola. Karena dalam suatu wisata tidak hanya bertujuan untuk mendapatkan laba sebesar-sebesarnya dalam jangka pendek, namun kelangsungan usaha tidak diketahui. Konsep pengembangan dengan pedoman pada aspek keberlanjutan dapat diupayakan sebagai dasar dalam pengelolaan wisata jonggol dalam jangka panjang.

\section{KESIMPULAN}

Berdasarkan potensi wilayah baik edukasi fisik dan non fisik kegiatan pengabdian di dusun Balangan terutama wisata jonggol yang memanjakan kearifan lokal yang ada secara alami, dapat dibuat menjadi kesimpulan Sudah tersedianya wahana outbond, sehingga saat sudah ada transaksi untuk kegiatan wisata sudah bisa digunakan. Sudah tersedianya wahana tempat pembuangan sampah di area wisata, karena wisata jonggol awalnya minim dalam pembuangan sampah. Sehingga bisa membantu melestarikan alam terutama yang ada di hulu. Sudah tersedianya tempat ibadah dan tempat istirahat.

\section{UCAPAN TERIMA KASIH}

Terima kasih kepada LP3M Universitas Muhammadiyan Yogyakarta yang telah memberikan Dana pengabdian skema KKN-PPM tahun anggaran 2018. Terima kasih kepada Dr. Suryanto.

\section{DAFTAR PUSTAKA}

Ashley, C. (2006). How Can Governments Boost the Local Economic Impacts of Tourism: Options and Tools: Toolkit. SNV Netherlands Development Organization [etc.]. Retrieved from

http://www.search4dev.nl/record 1284239

Assauri, S. (2012). Strategic Marketing

Sustaining Lifetime Customer Value. Jakarta: PT. Raja Grafindo Persada.

Creswell, J. W. (1994). Research Design-Qualitative,

Quantitative, and Mixed Method. London: SAGE Publications. 
Darsoprajitno, S. (2002). Ekologi Pariwisata. Bandung: Penerbit Angkasa.

Hasan, A. (2013). Marketing dan Kasus-Kasus Pilihan. Yogyakarta: Center for Academic Publishing.

Hermawan, H. (2016). Dampak Pengembangan Desa Wisata Nglanggeran Terhadap Ekonomi Masyarakat Lokal. Jurnal Pariwisata, 3(2), 105-117.

Hermawan, H. (2017a). Pengantar Manajemen Hospitality. Jawa Tengah: Penerbit NEM.

Hermawan, H. (2017b). Pengaruh Daya Tarik Wisata, Keselamatan dan Sarana Wisata Terhadap Kepuasan serta Dampaknya terhadap Loyalitas Wisatawan : Studi Community Based Tourism di Gunung Api Purba Nglanggeran. Wahana Informasi Pariwisata : Media Wisata, 15(1), 562-577.

Jafari, J., \& Ritchie, J. R. B. (1981). Toward a Framework for Tourism Education: Problems and Prospects. Annals of Tourism Research, 8(1), 13-34.

Kusumawardani, I. P., \& Hermawan, H. (2017). Kajian Tema Wisata Edukasi di Sindu Kusuma Edupark dari Perspektif Pemasaran Pariwisata. Open Science Framework.

Lukas, S. A. (2008). Theme Park. Reaktion Books.

Matthews, M. D., \& Boyns, T. (2001). A Schedule of the Lyndall Fownes Urwick Archive. The Management College, Henley.

Moleong, L. (1995). Metode penelitian. Bandung: Remaja Rosda Karya.

Prihatno, P. (2010). Memulihkan Citra Daerah Istimewa Yogyakarta untuk Meningkatkan Jumlah Wisatawan. Wahana Informasi Pariwisata: Media Wisata.

Sammeng, A. M. (2001). Cakrawala pariwisata. Balai Pustaka.
Statistik Kepariwisataan. (2015). D.I. Yogyakarta Indonesia: Dinas Pariwisata Daerah Istimewa Yogyakarta. Retrieved from http://visitingjogja.web.id/assets/ uploads/files/bank_data/Buku_S tatistik_Kepariwisataan_DIY_20 15_05092016040516.pdf, diakses 5 Juni 2017

Undang-Undang Nomor 10 Tahun 2009 Tentang Kepariwisataan, Sekretariat Negara. Jakarta § (2009). Indonesia.

Wijayanti, A. (2017). Analisis Dampak Pengembangan Desa Wisata Kembang Arum Terhadap Perekonomian Masyarakat Lokal. Tesis. Sarjana Wiyata Tamansiswa Yogyakarta.

Wiradiputra, F. A., \& Brahmanto, E. (2016). Analisis Persepsi Wisatawan Mengenai Penurunan Kualitas Daya Tarik Wisata terhadap Minat Berkunjung. Jurnal Pariwisata, 3(2), 129137.

Yahya, A. (2015). Sambutan Menteri Pariwisata R.I. pada Peringatan World Tourism Day dan Hari Kepariwisataan Nasional. Retrieved from http://kemenpar.go.id/asp/detil.a $\mathrm{sp} ? \mathrm{c}=125 \& \mathrm{id}=2975$

Cahyadi, W. 2009. Analisis \& Aspek Kesehatan Bahan Tambahan Pangan, Edisi Kedua. Jakarta: Bumi Aksara.

Eka, R. 2013. Rahasia Mengetahui Makanan Berbahaya. Jakarta: Titik Media Publisher.

Depdiknas. 2002. Sains. Jakarta: Pusat Kurikulum, Balitbang Depdiknas.

Putra, H. P dan Yebi, Y. 2010. Studi Pemanfaatan Sampah Plastik Menjadi Produk dan Jasa Kreatif. Jurnal Sains dan Teknologi Lingkungan. Vol. 2 No. 1.

Sukardi. 2004. Metodologi Pengabdian Pendidikan. Jakarta: PT. Bumi Aksara. 